\title{
GENETIC CONTROL OF THE MELANIC FORMS OF THE MOTH PHIGALIA PILOSARIA (PEDARIA)
}

\author{
D. R. LEES \\ Department of Zoology, University College of South Wales, Cardiff
}

Received 8.x.73

\begin{abstract}
SumMary
The two common melanic forms of the Pale Brindled Beauty Moth, Phigalia pilosaria (pedaria), in Britain are controlled by a pair of alleles. Dominance is complete and is in order of darkness; monacharia the extreme, unpatterned melanic is dominant to a patterned melanic, termed " intermediate", which is in turn dominant to the typical, non-melanic form. The two alleles control the coloration of the wings and the body of the male, and the body of the brachypterous female. Dilute individuals, where all the darker pigment is replaced by a golden yellow, occur in both melanic forms and typical. Such insects are homozygous for a dilute allele, recessive in effect, at a locus unlinked to monacharia.
\end{abstract}

\section{INTRODUGTION}

THE majority of the commonly occurring melanic forms of moths have been shown to be inherited as simple Mendelian dominants to typical (Doncaster, 1906; Adkin, 1911-12; Bowater, 1914; Onslow, 1921; Williams, 1932-33). In only a few species is it possible to separate reliably the heterozygote melanics from the homozygotes e.g. Polia nebulosa (Bowater, 1914).

In several species where more than one dominant melanic form occurs the genetic control has been shown to be due to multiple alleles. In Biston betularia, for example, Clarke and Sheppard (1964) and Lees (1968) have shown that two of the range of insects intermediate in appearance between typical and carbonaria, and collectively known as insularia, are controlled by alleles at the carbonaria locus. Carbonaria is completely dominant to insularia which is dominant to typical; nothing is yet known of the genetic relationships of light and dark insularia.

This paper is concerned with the two melanics of the Pale Brindled Beauty Moth; the extreme melanic monacharia and a lighter, slightly patterned morph referred to here as "intermediate" (this is probably equivalent to f. extinctaria Standfuss and f. obscurata Schawerda). The forms are illustrated in Lees (1971) where scoring criteria are also given. Little research has previously been carried out on the genetics of these melanics but Ford (1937) records the work of W. Buckley whose results suggest that monacharia is dominant to typical.

Most of my families were reared in terylene net sleeves placed over the boughs of Sallow (Salix spp.) trees; a few families were reared in the laboratory in wooden cages. Great care was always taken to prevent mortality from disease and starvation which, if selective, would affect the segregation ratios. 


\section{Results}

Details of the parentage, expected and observed segregations of the progeny and $\chi^{2}$ values for all families appear in table 1 . In no family does the observed segregation depart significantly from expectation.

TABLE 1

Crosses used in the investigation of the genetic control of the melanic forms of Phigalia pilosaria

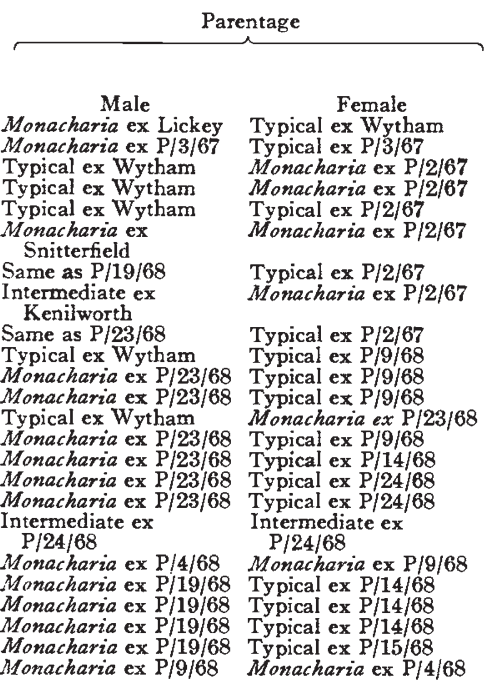

\begin{tabular}{|c|c|c|c|c|c|c|c|}
\hline & & Pro & & & & & \\
\hline Mon & aria & "Inte & iate" & Typ & ical & & \\
\hline$\sigma$ & $q$ & 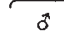 & 7 & 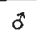 & $q$ & segregation & \\
\hline 45 & 38 & - & - & 43 & 26 & $1: 1$ & $\hat{1}-28$ \\
\hline 18 & 26 & - & - & 26 & 26 & $1: 1$ & $0 \cdot 67$ \\
\hline 55 & 45 & - & - & 49 & $5 \mathrm{t}$ & $1: 1$ & 0.00 \\
\hline 49 & 27 & - & - & 40 & 32 & $1: 1$ & 0.11 \\
\hline & & $\overline{10}$ & $\overline{14}$ & 96 & 78 & & \\
\hline 56 & 41 & 12 & 14 & - & 一 & $3: 1$ & 0.98 \\
\hline 17 & 22 & 21 & 16 & $\overrightarrow{30}$ & $\overline{18}$ & $1: 1$ & $0 \cdot 04$ \\
\hline 55 & $\overline{48}$ & 32 & 20 & 30 & 18 & $2: 1: 1$ & 0.19 \\
\hline- & - & 35 & 39 & 39 & 31 & $1: 1$ & $0 \cdot 10$ \\
\hline- & - & - & - & 87 & 89 & $\overline{1}$ & - \\
\hline 43 & 34 & - & - & 43 & 44 & 1:1 & $0 \cdot 60$ \\
\hline 19 & 17 & - & - & 21 & 17 & $1: 1$ & $0 \cdot 04$ \\
\hline 58 & 46 & - & - & 55 & 45 & $1: 1$ & 0.06 \\
\hline 23 & 25 & 29 & 36 & - & - & $1: 1$ & $2-54$ \\
\hline 3 & - & - & - & 2 & - & $1: 1$ & - \\
\hline 46 & 31 & - & - & 34 & 21 & $1: 1$ & 3.66 \\
\hline 42 & 39 & 42 & 40 & - & - & $1: 1$ & 0.00 \\
\hline- & - & 30 & 23 & 9 & 7 & $3: 1$ & $0 \cdot 12$ \\
\hline 95 & 89 & - & - & 34 & 28 & $3: 1$ & 0.00 \\
\hline 38 & 21 & 26 & 23 & - & - & $1: 1$ & 0.92 \\
\hline 50 & 51 & 65 & 39 & - & - & $1: 1$ & $0 \cdot 04$ \\
\hline 44 & 44 & 50 & 40 & - & - & $1: 1$ & 0.02 \\
\hline 33 & 27 & - & - & 38 & 27 & $1: 1$ & 0.20 \\
\hline 53 & 82 & - & - & 21 & 24 & $3: 1$ & 0.00 \\
\hline
\end{tabular}

(i) Dominance of monacharia and "intermediate" to typical

The 3 monacharia to 1 typical segregations of progeny in $P / 48 / 69$ and $\mathrm{P} / 65 / 69$ result from crossing monacharia males and females from broods in which the parents were monacharia and typical. The monacharia parents of these two families were therefore clearly heterozygous for typical. Among the melanic progeny there was no visible segregation into two classes; dominance is therefore complete.

Similarly the progeny of $\mathrm{P} / 44 / 69$ segregate into "intermediate" and typical in a $3: 1$ ratio. The only genetic interpretation of this must be that the parents, which were sibs, were heterozygous for typical. Again, no sign of a phenotypic difference between melanic homozygote and heterozygote appears in this brood; "intermediate" is thus completely dominant to typical.

In two families in which both parents were typical, $\mathrm{P} / 15 / 68$ and $\mathrm{P} / 10 / 69$, no segregation occurred among the progeny which were all typical (174 and 176 respectively). This confirms the recessiveness of typical since the parents of both families came from broods containing melanics.

(ii) Genetic relationship of monacharia and "intermediate"

The phenotypic expression of "intermediate" is relatively invariable, especially in comparison with the range of insularia forms in Biston betularia. It seems likely that a single gene controls " intermediate" throughout its range in Britain. The genetic relationship of "intermediate" to monacharia was analysed in samples from two localities in Warwickshire. 
A wild "intermediate" male from Kenilworth (Grid reference SP 290793) was crossed to two females; one a monacharia/typical heterozygote, the other typical (broods $\mathrm{P} / 23 / 68$ and $\mathrm{P} / 24 / 68$ ). The $1: 1$ " intermediate" to typical segregation in $\mathrm{P} / 24 / 68$ shows that the male was heterozygous. The segregation in $\mathrm{P} / 23 / 68$ does not depart significantly from 2:1:1. Such a segregation could occur if, (a) monacharia and "intermediate" were controlled by alleles with monacharia dominant to " intermediate", or (b) monacharia and "intermediate" were controlled by genes at separate loci with monacharia epistatic to "intermediate".

If $(a)$ applies, the genotypes of the parents may be represented:

$$
\text { male } C C^{t} \times \text { female } C^{M} C^{t}
$$

where $C$ is the locus controlling the colour of the wings in males and the thorax and abdomen in females. The alleles at $C$ are then as follows:

$$
\begin{aligned}
& C^{M} \text { monacharia } \\
& C \text { "intermediate" } \\
& C^{t} \text { typical. }
\end{aligned}
$$

This nomenclature follows that of Ford (1955). The progeny of $\mathrm{P} / 23 / 68$ would thus have the following genotypes: $C^{M} C, C^{M} C^{t}, C C^{t}, C^{t} C^{t}$.

If $(b)$ applies the parental genotypes may be represented:

$$
\text { male } m m \text { Ii } \times \text { female } M m i i
$$

where $I$ represents " intermediate", $i$ typical at the " intermediate" locus, $M$ monacharia and $m$ typical at the monacharia locus. The progeny of $\mathrm{P} / 23 / 68$

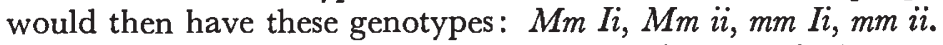

To test which of the alternatives $(a)$ or $(b)$ is applicable, monacharia from $\mathrm{P} / 23 / 68$ were crossed to typical. Two segregations of the progeny are possible if the genes controlling the two melanic forms are alleles: either monacharia and "intermediate" in a 1:1 ratio or monacharia and typical in a $1: 1$ ratio. Similarly two segregations may occur if the genes are at separate loci: monacharia and typical in a $1: 1$ ratio or monacharia, "intermediate" and typical in a $2: 1: 1$ ratio.

Seven crosses were made $(\mathrm{P} / 16 / 69, \mathrm{P} / 17 / 69, \mathrm{P} / 26 / 69, \mathrm{P} / 31 / 69, \mathrm{P} / 34 / 69$, $\mathrm{P} / 37 / 69, \mathrm{P} / 40 / 69$ ) of which five contained monacharia and typical among the progeny and two monacharia and " intermediate" (see table 1). From these results it is apparent that the segregations obtained in $\mathrm{P} / 31 / 69$ and $\mathrm{P} / 40 / 69$, where monacharia and "intermediate" are present in approximately equal numbers in both sexes, can only be explained on the assumption that the two melanic forms are controlled by alleles. Ford's (1955) convention for the nomenclature of multiple alleles may therefore be adopted (see $(a)$ above).

A monacharia male from Snitterfield (Grid reference SP 187605) was crossed to two females, one monacharia heterozygous for typical $(\mathrm{P} / 19 / 68)$ and the other typical $(\mathrm{P} / 22 / 68)$. The segregation in $\mathrm{P} / 22 / 68$ indicates that the male must have been heterozygous at the monacharia locus whether "intermediate" is an allele at it or not. If monacharia and "intermediate" were not allelic the male must have been homozygous at the "intermediate" locus. Otherwise typicals would occur among the progeny of $\mathrm{P} / 19 / 68$ but they do not. 
(a) On an allelic interpretation the parental genotypes of $\mathrm{P} / 19 / 68$ may thus be represented:

$$
\text { male } C^{M} C \times \text { female } C^{M} C^{t}
$$

giving four genotypes among the offspring: $C^{M} C^{M}, C^{M} C, C^{M} C^{t}, C C^{t}$.

(b) On a non-allelic interpretation the same brood may be represented:

male $M m I I \times$ female $M m$ ii.

Three genotypes would then appear among the offspring, $M M I i, M m I i$, and $m m I i$ in the ratio $1: 2: 1$ with the first two being phenotypically identical.

To test which of the alternatives $(a)$ and $(b)$ applies, four monacharia from $\mathrm{P} / 19 / 68$ were crossed to typical. The four broods were $\mathrm{P} / 52 / 69$, $\mathrm{P} / 55 / 69, \mathrm{P} / 56 / 69$ and $\mathrm{P} / 58 / 69$. In the first three of these monacharia and " intermediate" segregate in a $1: 1$ ratio while the fourth, $\mathrm{P} / 58 / 69$, contains monacharia and typical in approximate equality. Neither of these segregations could have been obtained if monacharia and "intermediate" are controlled at different loci but both are possible if the genes responsible are allelic.

(iii) Inheritance of dilute

In $\mathrm{P} / 40 / 69$, where monacharia and "intermediate" occur among the progeny in approximate equality, forms of both melanics appear in males and females in which the normal greenish black colour is diluted to a golden yellow. The proportion in the offspring is summarised in table 2 .

TABLe 2

Segregation of progeny in $\mathrm{P} / 40 / 69$

$\begin{array}{lcccccc}\text { Female } & & \overbrace{\text { Male }}^{\text {Monacharia }} & \text { Female } & \text { Total } \\ \text { Normal } & 33 & 27 & & 35 & 30 & 125 \\ \text { Dilute } & 9 & 12 & 7 & 10 & 38\end{array}$

The overall segregation of normally coloured moths to dilute does not depart significantly from $3: 1\left(\chi_{(1)}^{2}=0.123,0.8>\mathrm{P}>0.7\right)$, suggesting that dilute is inherited as a Mendelian recessive. A male and a female from $\mathrm{P} / 40 / 69$, both dilute monacharia, were crossed (P/1/70). Five adult progeny were eventually obtained all of which were dilute. Two of these were recognisable as typical males the darker parts of which were replaced by golden yellow. The fact that all five progeny in $\mathrm{P} / 1 / 70$ were dilute is confirmation of the recessive inheritance of this character. The segregation in $\mathrm{P} / 40 / 69$ suggests that dilute assorts independently of the $C$ locus. The dilute locus may therefore be given the identity $D$ where $D^{y}$ represents the dilute and $D^{Y}$ the normal allele. The genotypes of the parents of $\mathrm{P} / 40 / 69$ at the two loci affecting imaginal colour are then:

$$
\text { male } C^{M} C D^{Y} D^{y} \times \text { female } C^{t} C^{t} D^{Y} D^{y} \text {. }
$$

\section{Discussion}

The dominance of monacharia to typical in the stock reported here confirms the finding of W. Buckley with Barnsley (Yorkshire) stock, recorded in Ford (1937). Buckley reared a small family from a monacharia $\times$ monacharia pairing; 
the progeny consisted of 9 monacharia and 2 typical. The genetic relationship of the "intermediate" form to both monacharia and typical has not hitherto been reported.

The similarity of the genetic control of the melanic forms of $P$. pilosaria and those of $B$. betularia is striking: in both, multiple alleles are responsible with dominance increasing in order of darkness. The species differ inasmuch as insularia in $B$. betularia contains a large range of forms controlled by at least two, and probably more, alleles, whereas "intermediate" in $P$. pilosaria are relatively invariable and seem to be under the control of a single allele.

In the aposematic Two-spot Ladybird, Adalia bipunctata, the two common melanic forms are also controlled by a pair of alleles with the blackest dominant to a less black form which is in turn dominant to the normal red form (Lus, 1928; Creed, 1966).

In this study it has usually been possible to identify the autosomally controlled melanic forms of $P$. pilosaria in the brachypterous female where the genes affect the colour-pattern of the abdomen and thorax. Occasionally, however, difficulty has been encountered in separating typicals of this sex from "intermediate"; in some broods the typicals are dark brown dorsally with little sign of any patterning. At first it was thought possible that such forms represented a melanic inherited only in the females, as reported by Bretschneider (1939). Subsequent crosses did not confirm this but showed that the colour of the dorsal abdomen and thorax in females varies continuously. This variability is greater than that shown by the abdomen of males and the possibility cannot be excluded that at least some of the expression of the genes concerned is sex-controlled. The colour-pattern of the ventral surface of the abdomen is a much more reliable scoring criterion in females than the dorsal surface (Lees, 1971). Bretschneider's description of the melanic (melanaria) females in his stock suggests that these were phenotypically different from the melanic forms used in this investigation. They had white scaling on the dorsal surface of the abdomen, particularly at its tip, which both monacharia and " intermediate" females lack.

The dilute forms of melanic $P$. pilosaria resemble similar forms occurring rarely in $B$. betularia (Cockayne, 1940). Males identical to the dilute forms in $\mathrm{P} / 40 / 69$ and $\mathrm{P} / 1 / 70$ have not so far occurred in samples of a survey of this species in Britain (Lees, 1971) which suggests that dilute either occurs at low frequency or is just a rare mutant. Occasionally, especially in S.W. Wales males similar to dilute monacharia but slightly darker than those in $\mathrm{P} / 40 / 69$ are found. It is not yet known whether these are homozygous for the dilute allele.

Acknowledgments.-All of the work reported here was carried out at the Department of Zoology, Oxford; I thank Professor J. W. S. Pringle, F.R.S. for the facilities he provided. I am indebted to Professor E. B. Ford, F.R.S. and Dr H. B. D. Kettlewell for their help and encouragement. Miss Gillian Brookes assisted, with great care, in the rearing of P. pilosaria families. I am particularly grateful to $\mathrm{Dr}$ E. R. Creed for many profitable discussions and for reading the paper in draft form.

\section{REFERENGES}

AdkIN, R. 1911-12. (Report of exhibit.) Proc. S. Lond. ent. nat. Hist. Soc., pp. 151-152. BOWATER, w. 1914. Heredity of melanism in Lepidoptera. F. Genet., 3, 299-315. 
BRETSCHNEIDER, R. 1939. Neues uber Melanismus der Schmetterlinge im Gau Sachsen. 1. Geschlechtsbegrentzer, dominanter Melanismus beim $q$ von Phigalia pedaria F. Ent. Z. Frankf. a.M., 53, 59-60.

CLARKE, C. A., AND SHEPPARD, P. M. 1964. Genetic control of the melanic form insularia of the moth Biston betularia. Nature, 202, 215-216.

COCKAYNE, E. A. 1940. The buff forms of Biston betularia L., ab. lomasaria, Cottam, and ab. decolorata n. ab. Their history and genetics. Entomologist's Rec. F. Var., 52, 93-96. CREED, E. R. 1966. Geographic variation in the Two-spot Ladybird in England and Wales. Heredity, 21, 57-72.

DONCASTER, L. 1906. Collective enquiry as to progressive melanism in Lepidoptera. Entomologist's Rec. F. Var., 18, 165-168.

FORD, E. B. 1937. Problems of heredity in the Lepidoptera. Biol. Rev., 12, 461-503.

FORD, E. B. 1955. A uniform notation for the human blood groups. Heredity, 9, 135-142.

LEES, D. R. 1968. Genetic control of the melanic form insularia of the Peppered Moth, Biston betularia (L.). Nature, 220, 1249-1250.

LEES, D. R. 1971. The distribution of melanism in the Pale Brindled Beauty Moth, Phigalia pedaria, in Great Britain. In Ecological Genetics and Evolution (edit. by Creed. E. R.), pp. 152-174. Blackwell, Oxford.

LUS, J. J. (LUSIS). 1928. On the inheritance of colour and pattern in lady beetles Adalia bipunctata L. and Adalia decempunctata L. (Russian with English summary). Bulletin of the Bureau of Genetics, Leningrad, 6, 89-163.

onsLOw, THE HON. H. 1921. Inheritance of wing colour in Lepidoptera, VI. 7. Genet., 11, 277-292.

wilitams, н. в. 1932-33. Notes on Boarmia repandata and Boarmia rhomboidaria. Proc. S. Lond. ent. nat. Hist. Soc., pp. 1-10. 